\title{
Optimal Polypropylene Fiber Content for Improved Compressive and Flexural Strength of Concrete
}

\author{
Anthony Nkem Ede ${ }^{1}(\mathrm{PhD})$ and AbimbolaOluwabambi Ige ${ }^{1}$ \\ ${ }^{I}$ Department of Civil Engineering, College of Science and Technology, Covenant University, Canaan Land, KM \\ 10, Idiroko Road, P.M.B. 1023 Ota, Ogun state, Nigeria
}

\begin{abstract}
Worldwide, concrete is a very important construction material, impacting heavily on Gross Domestic Products of many nations: a $\$ 30$ billion business for ready-mix concrete production industry per year in the United States and a cement consumption rate of about 106kg per person in Nigeria. It is therefore imperative that this important material in the world construction industry must also be endued with the best possible properties. The principles on which reinforced concrete structural designs were based hangs on quality concrete material used in conjunction with quality steel or reinforcing material. However, in Nigeria, the reinforcement steel commonly used is of poor qualities as recent researches have shown that over $40 \%$ of 12 mm and $16 \mathrm{~mm}$ used within Lagos in 2010 failed the 460N/mm yield strength bench mark of BS8110 of 1997. The employment of micro fibers in the concrete will improve the strength and compensate for the apparently declining strength of Nigerian reinforced concrete building constructions and will also improve the strength of the non-reinforced concrete-sand crate block buildings. This research studies the effects of micro synthetic polypropylene fiber in improving concrete strength with the main focus of identifying the optimal quantity for improved compressive and flexural strengths of concrete. Destructive and non-destructive compressive strength tests and destructive flexural strength tests were carried out on the samples built with $0.25 \%, 0.5 \% 0.75 \%$ and $1 \%$ contents of polypropylene fibers alongside a control samples after 7, 14, 2128 days of curing. The optimal percentage of polypropylene fiber that produced improved compressive and flexural strengths were found to lie within $0.25 \%$ and $0.5 \%$.
\end{abstract}

Keyword: Concrete, Polypropylene Fiber, Destructive Test, Non Destructive Tests, Compressive Strength, Flexural Strength

\section{Introduction}

Concrete is the most used building material worldwide with its usage doubling the combined consumption of wood, steel, aluminum and plastics. Activities linked to concrete, from the production of the constituent materials to the end user applications produces millions of jobs opportunities worldwide and contributes immensely to the Gross Domestic Product (GDP) of most nations of the world. It is the most used man-made product in the world and the mover of world economy as it is one of the basis of large commercial industries.According to the US National Ready Mixed Concrete Association, in the United States alone, readymix concrete production generates over $\$ 30$ billion per year for the concrete industry. In Nigeria, majority of the structures are constructed using concrete with a consumption rate of cement estimated at $106 \mathrm{~kg}$ per person as at 2011. The massive use of concrete in Nigerian building industry is typified by the very high rate of over $95 \%$ cases of building collapses verified in Nigeria affecting concrete houses [1]. The vast size of the concrete industries worldwide and the ever evolving ways in which concrete is being used continually since its discovery as a construction material makes it difficult to overstate the importance of this material.

Concrete is made up of cement, aggregates and water. Fine and coarse aggregates are mixed with cement, usually Portland cement and water to produce a composite material. Cement and water mixes to form the paste that serves as a binder to the aggregates. After mixing, the paste-aggregate combination hardens and gains strength to form rock-like masses due to a chemical process known as hydration. As water reacts with cement to form the matrix of the composite material, hydration of the paste enhances bond of the other components and confers greater strength to the mix over time. The resulting product is one of the most durable building materials as concrete structures have a long service life of up to 100 years approximately. It is fire resistant especially when compared to wood. Concrete is good in compression, but very weak in tension and under flexural stress and so it is usually reinforced with materials that are strong in tension (conventionally steel bars but in recent times with fibers). The combination of concrete and reinforcing bars gives rise to reinforced concrete which marked a major advancement in the construction industry and paved way to modern complex structures. Concrete serving as matrix in the composite material absorbs the compressive stress and protects the reinforcement from corrosion while the steel is able to distribute the tensile stresses that cause concrete to crack and ultimately fail. This versatile composite product has been the most important materials used in the construction of complex structural members around the globe for several years [2]. 


\subsection{Fiber Reinforced Concrete}

Concrete is very brittle in nature with the consequent low crack resistance which have limited its use only to absorbing compressive stresses. The idea of adding additives to concrete to improve its strength have been employed for many centuries. Concrete additives have been used since Roman and Egyptian times, when it was discovered that adding volcanic ash to the mix allowed it to set underwater, while adding horse hair made concrete less liable to crack and the adding of blood made it more frost-resistant. More recent days additives started with asbestos until it cancer-related hazards were discovered. In the most recent times, many methods have been adopted to improve concrete properties, and one of such methods is the addition of fibers to concrete. Research into the types of fibers to be used in concrete applications have been intensified since the 1950s alongside researches on the improvement of the composite materials technologies. For over half a century, extensive researches were undertaken to determine the appropriate qualities of fibers needed for various applications. The qualities of fibers needed for fiber reinforced concrete has been one of the major topics of interest because of the importance of concrete to the construction industries. Various types of fiber materials such as steel, carbon, glass, plastic, polypropylene, nylon, and cotton were tested. From the results of these research, American Concrete Institute's Committee 544 [3] classified fiber reinforced concrete into four groups based on the fiber materials: steel fiber reinforced Concrete (SFRC), glass fiber reinforced concrete (GFRC), synthetic fiber reinforced concrete (SNFRC), and natural fiber reinforced concrete (NFRC). Synthetic fibers such as polyester, acrylic, polyethylene and polypropylene are further subdivided into micro-synthetic fibers (for diameter less than $0.30 \mathrm{~mm}$ ) and macro-synthetic fibers (for diameter greater than $0.30 \mathrm{~mm}$ ), [4]. Glass and natural fibers show vulnerability to temperature variation and environmental conditions, respectively, leaving steel and synthetic fibers as the most viable concrete reinforcement options.

Generally, the introduction of fibers into the concrete mix have proved to considerably improve the ductile behaviour of concrete materials. Under pure compressive loads and low tensile stress, the addition of fibers has little effect [5]. Conversely, the addition of fiber leads to substantial increases in the ductility of concrete [6] and [7]. This significantly improves the crack control as it reduces the crack widths and crack spacing in the concrete which in turn reduces the ingress of water and chemicals that are known to be harmful to concrete thereby improving the long term serviceability and durability of built structures [8], [9], [10] and [11]. The reduction of crack growth through the adoption of fibers is a comforting news to the building industry as many infrastructures are beginning to age. This is of particular importance as infrastructures deteriorate and the built environment is grossly unable to sustain the service lives originally planned for most structures [12]. Fibers in concrete have proved useful to controlling crack growth by inhibiting plastic and drying shrinkage from taking place thereby reducing the permeability of concrete. The application of fiber reinforced concrete are indispensable in all concrete constructions under mixed and heavy loadings and where tensile stresses are common such as roadways, warehouses, driveways, sidewalks, runways, taxiways, dams, storm-water structures, mining and tunneling structures, storage structures, etc. Researches have proved that the impacts of overloads on road pavements can be very devastating [13]. This is because most of the seemingly concentrated compressive loads end up generating tangential stresses that create crack prone tensions.

\subsection{Synthetic Fibers}

Synthetic fibers are man-made fibers consequential of petrochemical and textile industries activities. Synthetic fibers used for reinforcing concrete derives from assortment of formulations of organic polymers [14]. They are the products of researches to improve on naturally occurring fibers. The raw materials derive from petroleum based chemicals. These materials are polymerized into a long, linear chemical that bond adjacent carbon atoms. Synthetic fiber that have been experimented in Portland cement concrete matrices include acrylic, aramid, carbon, nylon, polyester, polyethylene and polypropylene. Research and field application of these fibers depended mainly of their availability while those that have found commercial applications have been object of extensive reporting. This research will be focused on the use of micro synthetic polypropylene fiber to improve concrete strength.

Polypropylene (PP), is athermoplasticpolymer used in a wide variety of applications such as textiles (rope and carpets), packaging, labelling, stationary, containers, automotive parts and banknotes. Polypropylene fiber derive from synthetic hydrocarbon polymer through extrusion processes of hot drawing the material through a die. In the production process and based on the properties required, copolymerization among the monomers is necessary for the desired properties to be achieved [15]. It is adopted because of its tensile and flexural strength capability of arresting plastic shrinkage cracks. It has been established that the addition of randomly distributed polypropylene fibers to brittle cement based materials can increase their fracture toughness, ductility and impact resistance [16]. 


\subsection{Statement of Problem of this Research}

Worldwide, concrete is a very important construction material, impacting heavily on world's GDPs: a $\$ 30$ billion business for ready- mix concrete production industry per year in the United States, a cement consumption rate of $106 \mathrm{~kg}$ per person in Nigeria. It is therefore imperative that this material that is so important in the world construction industry must also be endued with the best possible properties. The principles on which reinforced concrete structural designs were based hangs on quality concrete material used in conjunction with quality steel or reinforcing material. However, in Nigeria, the reinforcement steel commonly used is of poor qualities as recent research [17] has shown that over $40 \%$ of $12 \mathrm{~mm}$ and $16 \mathrm{~mm}$ used within Lagos in 2010 failed the $460 \mathrm{~N} / \mathrm{mm}^{2}$ yield strength bench mark of BS8110 of 1997 , the official reinforced concrete code of Nigeria. The same research showed over $30 \%$ failure for the lowered $410 \mathrm{~N} / \mathrm{mm}^{2}$ yield strength suggested by the professionals of the building industry in Nigeria. This occurring at a time when the advanced nations such as UK with all it high technology in material production and testing have migrated from $460 \mathrm{~N} / \mathrm{mm}^{2}$ yield strength bench mark to $500 \mathrm{~N} / \mathrm{mm}^{2}$. Therefore, faced with the declining quality of steel reinforcing bars in Nigerian, the only way to improve the quality of reinforced concrete structures in Nigeria is to improve the quality of concrete materials. The employment of fibers in the concrete will improve the strength and compensate for the apparently declining strength of Nigerian reinforced concrete building constructions. Fibers in concrete will also improve the strength of the non-reinforced concrete-sand crate block buildings that are common in the rural areas and very often infested with cracks due to the poor quality of concrete adopted.

This research therefore studies the effects of micro synthetic polypropylene fiber in improving concrete strength. The main focus being on the optimal quantity of polypropylene fiber for improved compressive and flexural strengths of concrete. Destructive and non-destructive tests were carried out on the samples after 7, 14, 2128 days of curing. Compressive strength tests and flexural strength tests were performed on the polypropylene fiber reinforced concrete alongside a control sample. The results between both the control and the test samples are then assessed via statistical tools.

\subsection{Laboratory Works}

\section{Material And Technology}

This section presents a brief summary of the laboratory study carried out in this research work. All the tests were performed over a period of 40 days in the Civil Engineering Department, Covenant University Ota, Nigeria. The tests that were carried out include Schmidt rebound hammer non-destructive tests and the destructive tests made up compressive test and modulus of rupture test. Portland cement, fine aggregate made up sharp sand and coarse aggregate of 3.5 inches granite were used. The cement, sand, and gravel were mixed in the ratio 1:2:4 by weight, while the water/cement ratio used was 0.5 . A total of 40 cubes fabricated in steel moulds of dimension $150 \times 150 \times 150$ were used for the non-destructive tests and the compressive tests. Twelve (12) beams of dimensions $350 \mathrm{~mm} \times 100 \mathrm{~mm} \times 100 \mathrm{~mm}$ for length, width and height respectively were prepared for the flexural tests.

\subsection{Casting and Curing of Samples}

Five different samples, each containing a different percentage of polypropylene fibre $(0 \%, 0.25 \%$, $0.5 \%, 0.75 \%$, and $1 \%$ ) produced for the concrete compressive tests. Eight cubes were made for each sample just as two cubes were selected for the 7,14,21, and 28 days compressive strength test respectively. The mixing was done with the aid of a mechanical mixer as to guarantee good quality, given that the presence of fibre makes manual mixing difficult. The respective weight of all materials used for cube casting are provided in table 1 below.

Table 1: showing the weights of materials used in each mix for concrete cubes

\begin{tabular}{|l|l|l|l|l|l|}
\hline & $\begin{array}{l}\text { MIX 1 } \\
\text { (CONTROL) }\end{array}$ & $\begin{array}{l}\text { MIX 2 } \\
\mathbf{( 0 . 2 5 \% )}\end{array}$ & $\begin{array}{l}\text { MIX 3 } \\
\mathbf{( 0 . 5 \% )}\end{array}$ & $\begin{array}{l}\text { MIX 4 } \\
(\mathbf{0 . 7 5 \% )}\end{array}$ & $\begin{array}{l}\text { MIX5 } \\
(\mathbf{1 \% )}\end{array}$ \\
\hline Polypropylene & - & $44 \mathrm{~g}$ & $88 \mathrm{~g}$ & $132 \mathrm{~g}$ & $176 \mathrm{~kg}$ \\
\hline Cement & $8800 \mathrm{~g}$ & $8800 \mathrm{~g}$ & $8800 \mathrm{~g}$ & $8800 \mathrm{~g}$ & $8800 \mathrm{~g}$ \\
\hline Sand & $17600 \mathrm{~g}$ & $17556 \mathrm{~g}$ & $17512 \mathrm{~g}$ & $17468 \mathrm{~g}$ & $17424 \mathrm{~g}$ \\
\hline Granite & $35200 \mathrm{~g}$ & $35200 \mathrm{~g}$ & $35200 \mathrm{~g}$ & $35200 \mathrm{~g}$ & $35200 \mathrm{~g}$ \\
\hline Water & $4500 \mathrm{~g}$ & $4500 \mathrm{~g}$ & $4500 \mathrm{~g}$ & $4500 \mathrm{~g}$ & $4500 \mathrm{~g}$ \\
\hline
\end{tabular}

For the 12 beams casted for flexural strength, the tests were carried out after 14 and 28 days. Three percentages of polypropylene fibres adopted for the beams are $0 \%, 0.5 \%$ and $1 \%$. The weight of the materials for the $0 \%, 0.25 \%, 0.5 \%$ and $1 \%$ polypropylene fibres are shown in the table 2 below. 
Table 2: showing the weights of materials used in each mix for the beams

\begin{tabular}{|l|l|l|l|l|}
\hline & $\begin{array}{l}\text { MIX 1 } \\
\text { (CONTROL) }\end{array}$ & $\begin{array}{l}\text { MIX 2 } \\
(\mathbf{0 . 2 5 \%})\end{array}$ & $\begin{array}{l}\text { MIX 3 } \\
(\mathbf{0 . 5 \%})\end{array}$ & $\begin{array}{l}\text { MIX4 } \\
(\mathbf{1 \% )}\end{array}$ \\
\hline Polypropylene & - & $44 \mathrm{~g}$ & $88 \mathrm{~g}$ & $176 \mathrm{~kg}$ \\
\hline Cement & $8800 \mathrm{~g}$ & $8800 \mathrm{~g}$ & $8800 \mathrm{~g}$ & $8800 \mathrm{~g}$ \\
\hline Sand & $17600 \mathrm{~g}$ & $17556 \mathrm{~g}$ & $17512 \mathrm{~g}$ & $17424 \mathrm{~g}$ \\
\hline Granite & $35200 \mathrm{~g}$ & $35200 \mathrm{~g}$ & $35200 \mathrm{~g}$ & $35200 \mathrm{~g}$ \\
\hline Water & $4500 \mathrm{~g}$ & $4500 \mathrm{~g}$ & $4500 \mathrm{~g}$ & $4500 \mathrm{~g}$ \\
\hline
\end{tabular}

For the casting, the weighed water, sand, cement, polypropylene fibres, granite are poured into the mixer in that order. The polypropylene fibres were poured in small bits to ensure even distribution while the mixing is continued for about 5-10 minutes. The concrete mix is then poured into the mould in 3 layers. Each layer is tamped with a tamping rod 25 times and the excess layer on top is removed with a trowel. The concrete specimens were marked and stored in moist air for 24 hours. They are then removed from their moulds and placed in curing tanks. The concrete specimens are kept submerged in water in the curing tanks until a few hours prior to their respective tests.

\subsection{Testing}

The non-destructive tests were done with the aid of a Schmidt/rebound hammer. The concrete cubes were allowed to dry for a few hours before testing. The surfaces are cleaned to ensure the surfaces are smooth. The Schmidt hammer is impacted onto the surface of the concrete in order to determine its rebound value. The Schmidt hammer is impacted on different spots on the concrete cube and the average rebound values are computed and recorded. The corresponding compressive strength is red off from a conversion chart. For the destructive compressive tests, the cubes were placed on the compression testing machine and loads gradually applied till the specimens failed and the compressive strength obtained and recorded. The compressive strengths acquired from the destructive tests are obtained by dividing the crushing loads by the area of the cube as expressed below:

Compressive strength $=\frac{\text { crushing load }}{\text { area of the cube }}$

1

Test apparatus for the compressive tests are shown in figure 1.

The flexural strength, also known as modulus of rupture or bends strength, or fracture strength is a mechanical parameter for brittle materials that indicates a material's ability to resist deformation under load. A three point bending setup was used for this research. Calculations of the flexural strength, $\mathrm{F}\left(\mathrm{N} / \mathrm{mm}^{2}\right)$ is obtained as

$\mathrm{F}=\frac{\mathrm{PL}}{\mathrm{bd}^{2}}$

where,

$\mathrm{P} \quad$ is the load at fracture point $(\mathrm{N})$

$\mathrm{L} \quad$ is the length of the support span ( $\mathrm{mm}$ )

$\mathrm{b} \quad$ is the width of the beam ( $\mathrm{mm})$

$\mathrm{d} \quad$ is the thickness of the beam (mm)

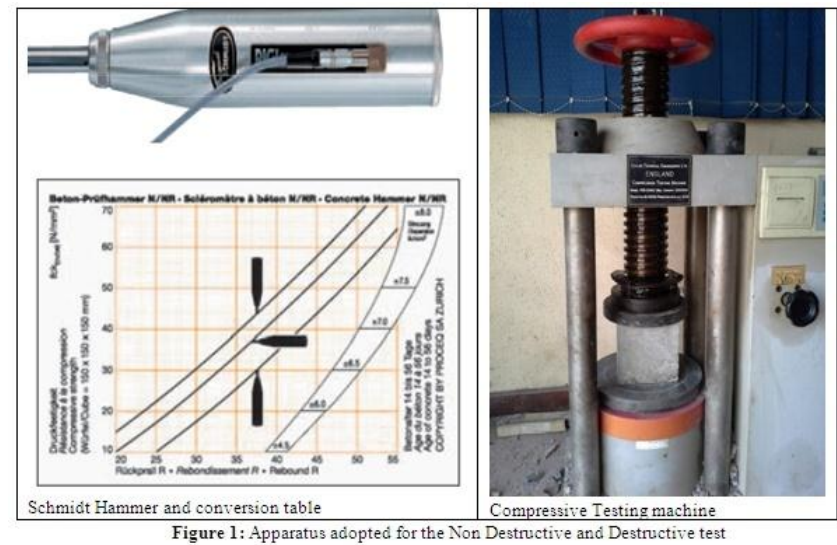




\subsection{Compressive strengths}

\section{Results And Discussion}

This section analyzes the results obtained in the experiments carried out as stated in the previous section. Table 3 shows the crushing loads for the different percentages of polypropylene reinforced concrete cubes (PFRC) ( for $0 \%, 0.25 \%, 0.5 \%, 0.75 \%$, and $1 \%$ ) from $7,14,21$, and 28 days tests.

Table 3: shows the crushing loads for the different percentages of polypropylene

\begin{tabular}{|c|l|l|l|l|l|l|l|l|l|l|l|}
\hline \multicolumn{2}{|l|}{ Table Showing The Crushing Loads Of Different Percentages Of Pfrc } \\
\hline
\end{tabular}

Figure 2 shows the compressive strengths of the different percentages of polypropylene fiber reinforced concrete cubes for $7,14,21$, and 28 days of age.

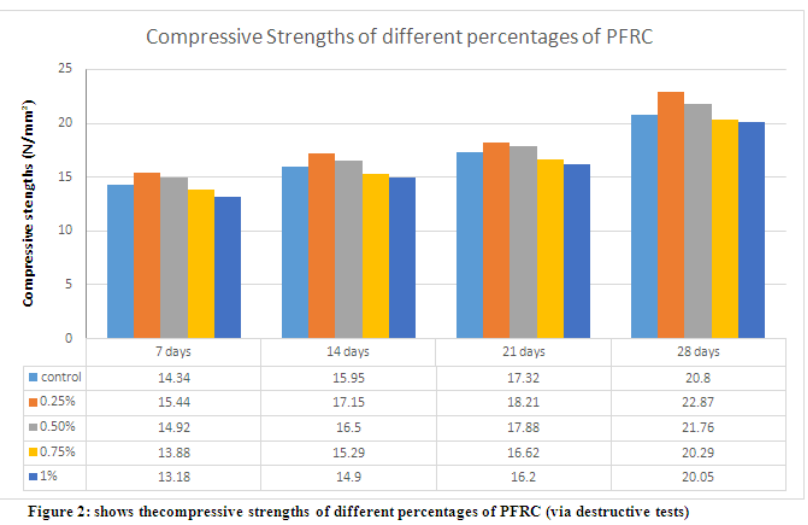

Figure 2: shows thecompressive strengths of different percentages of PFRC (via destructive tests)

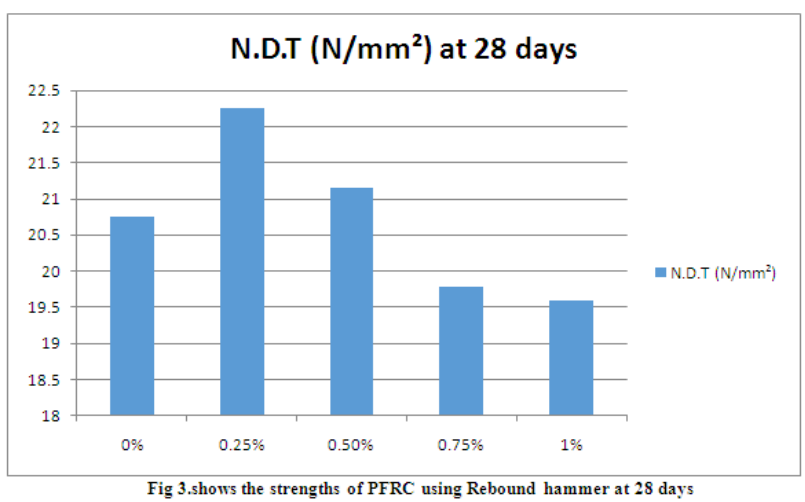

From the results, it is observed that the addition of polypropylene fiber in the concrete mix has an effect on the compressive strengths of concrete. Addition of polypropylene in low percentages, about $0.25 \%$, increases the compressive strength by about $5 \%$ to $10 \%$, while addition of $0.5 \%$ increases the compressive by about $3 \%$ to $5 \%$. However, the compressive strength decreases by about $2 \%$ to $4 \%$ when $0.75 \%$ of polypropylene fibers are added and by 4 to $8 \%$ when $1 \%$ of polypropylene fibers are added.

The results of the non-destructive tests follows the same pattern of the destructive test in that the addition of polypropylene fibers at a dosage of $0.25 \%$ increases the strength by 5 to $9 \%$; dosage of $0.5 \%$ increased the strength from 3 to $5 \%$. The strength decreases by about 2 to $4 \%$ when $0.75 \%$ of polypropylene fibers are added and by 4 to $8 \%$ when $1 \%$ of polypropylene fibers are added. The rebound hammer 28 days results are shown in figure 3 . 
Table 4 shows the relationship between the destructive strength and the non-destructive strength at the 28 days while figure 4 compares the destructive tests and non-destructive tests for 28 days of age with the linear regression line shown. It is safe then to say that the increase in compressive strength is due to increased bonding effect between the fiber and the concrete matrix which made for better transference of stress between the aggregates thereby unlocking the full potential to resist stress. As the amount of fiber exceeded the optimal value, the excess fiber weakens the aggregate interlock thereby reducing the strength of the concrete.

Table 4: Table Showing the Strengths Obtained by Destructive Tests and N.D.T (28 Days)

\begin{tabular}{|l|l|l|}
\hline & N.D.T $\left(\mathrm{N} / \mathrm{mm}^{2}\right)$ & DESTRUCTIVE TEST $\left(\mathrm{N} / \mathrm{mm}^{2}\right)$ \\
\hline CONTROL & 20.75 & 20.8 \\
\hline $0.25 \%$ & 22.25 & 22.87 \\
\hline $0.50 \%$ & 21.16 & 21.76 \\
\hline $0.75 \%$ & 19.78 & 20.29 \\
\hline $1 \%$ & 19.59 & 20.05 \\
\hline
\end{tabular}

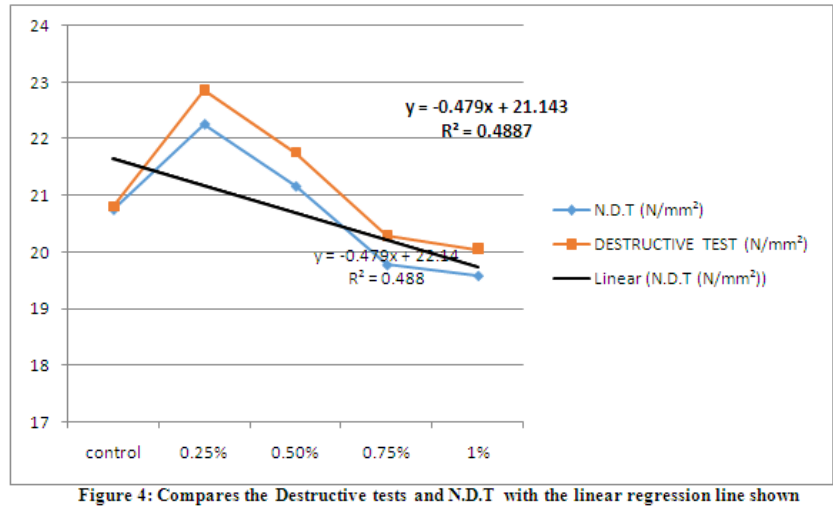

\subsection{Flexural strengths}

For the flexural strength, a three point bending setup was used. Figure 6 shows the flexural strengths for 14 days and 28 days respectively.

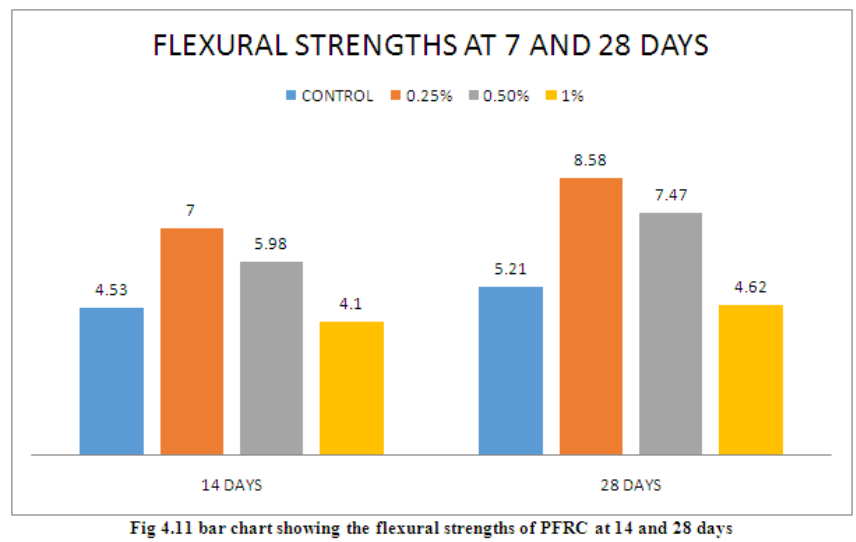

From the results, it is observed that the addition of polypropylene fiber in the concrete mix has a positive effect on the flexural strengths of concrete. Addition of polypropylene in low percentages, about $0.25 \%$, increases the flexural strength by about 55\% to $65 \%$, while addition of $0.5 \%$ increases the compressive by about $32 \%$ to $44 \%$. However, the flexural strength decreases by about $9.5 \%$ to $11.5 \%$ when $1 \%$ of polypropylene fibers are added. It is safe to say that the increase in strength is due to additional load absorbed by the fibers present in the concrete matrix.

\section{Conclusion}

The primary objective of this study was to evaluate the optimal quantity of polypropylene fibers for improved physical and mechanical behavior of concrete. The addition of marginal quantity of polypropylene fiber in the concrete mix showed positive effects on the compressive strengths of concrete. The optimum percentage of polypropylene to be added to the concrete mix to increase the compressive strength lies around 
0.25\%. Polypropylene fibers increased the 28 days compressive strength of concrete by about $9 \%$. Polypropylene fiber addition greater than the optimum percentage $(0.25 \%)$ showed a slight increase for $0.50 \%$ and then decreased for higher values. The flexural strength of concrete increases by as much as $65 \%$ when low percentage fractions $(0.25 \%)$ are added. It recorded slight increase for $0.50 \%$ and then decreases when $0.75 \%$ and $1 \%$ are added. From this study, it is observed that the optimum dosage of polypropylene fiber is between $0.25 \%$ and $0.5 \%$ both for compressive strengths and for flexural strengths. Further researches should be carried out to know the exact dosage of polypropylene fibers that yields the most favorable strengths of concrete and to apply this methodology to different types of Portland cements.

\section{Reference}

[1]. Anthony Nkem Ede and Joshua OmoruyiOkundaye, Appraisal of Timber as Structural Members for Residential Buildings in Nigeria, International Journal of Engineering \& Technology, Vol:14 No:01 1082014.

[2]. Anthony Nkem Ede,Samuel Olusegun Adebayo ${ }^{1}$, Emmanuel Ikechukwu Ugwu ${ }^{1}$ and ChidoziePraiseGodEmenike, Life Cycle Building Assessment of Environmental Impacts of Using Concrete or Timber to Construct a Duplex Residential, IOSR Journal of Mechanical and Civil Engineering Volume 11, Issue 2 Ver. I 2014.

[3]. ACI committee 544 Report. American Concrete Institute State-of-the-Art Report on Fiber Reinforced Concrete, reported by the ACI Committee 544, ACI 544.1R-96, reapproved 2002.

[4]. Richardson, A.E., and Landless, S., (2009). Synthetic fibers and steel fibers in concrete with regard to bond strength and toughness. North Umbria Working Paper Series: Interdisciplinary Studies in the Built and Virtual Environment, December 2009, pp. 128-140.

[5]. Nataraja, M. C., Dhang, N., and Gupta, A. P. "Stress-strain curves for steel-fiber reinforced concrete under compression." CementConcrete Composite, vol. 21, issue 5-6, December 1999, p. 383-390.

[6]. Shah, S. P., and Rangan, B. V. Fiber reinforced concrete properties. ACI Journal, 68(2), 1971, pp. $126-137$.

[7]. Thomas, J., and Ramaswamy, A. Mechanical properties of steel fiber-reinforced concrete. Journal of Materials in Civil Engineering, 19(5), May 2007, pp. 385-392.

[8]. Grzybowski, M., and Shah, S. P. Shrinkage cracking on fiber reinforced concrete. ACI Materials Journal, 87(2), March-April 1990, pp. 138-148.

[9]. Banthia, N., Azabi, M., and Pigeon, M. Restrained shrinkage cracking in fiber reinforced cementitious composites. Materials and Structures, 26(7), August 1993, pp. 405-413.

[10]. Johnston, C. D. Fibre-reinforced cements and concretes. Ottawa, Ontario, Canada: (2001), Gordon and Breach Science Publishers, $372 \mathrm{p}$.

[11]. Susetyo, J., Gauvreau, P., and Vecchio, F. J. Effectiveness of steel fiber as minimum shear reinforcement. ACI Structural Journal, 108(4), July-August 2011, pp. 488-496.

[12]. Wang, Y., Backer, S., and Li, V. C. An experimental study of synthetic fibre reinforced cementitious composites. Journal of Materials Science, 22(12), December 1987, pp. $4281-4291$.

[13]. Anthony Nkem Ede. Cumulative Damage Effects of Truck Overloads on Nigerian Road Pavement, International Journal of Civil \& Environmental Engineering,Vol: 14, 2014.

[14]. American concrete institute, ACI Committee 544.1R, 1996.

[15]. Sabu Thomas, Visakh P. M. Handbook of Engineering and Specialty Thermoplastics: Volume 3: Polyethers and Polyesters ISBN: 9781118104736, Co-published by John Wiley \& Sons, Inc. Hoboken, New Jersey, and Scrivener Publishing LLC, Salem, Massachusetts, 2011

[16]. Saeed Ahmed*, Imran A Bukhari, Javed Iqbal Siddiqui, Shahzad Ali Qureshi, University of Engineering \& Technology Taxila, Pakistan. A Study on Properties of Polypropylene Fiber Reinforced Concrete; 31st Conference on our World in Concrete \& Structures: 16 -17 August 2006, Singapore

[17]. Anthony Nkem Ede, OluwarotimiMichealOlofinnade, Opeyemi Joshua, Experimental Investigation of Yield Strengths of Steel Reinforcing Bars Used in Nigerian Concrete Structures, International Journal of Scientific \& Engineering Research, Volume 5, Issue 4, 2014. 